\title{
BMJ Open Quality Severe illness getting noticed sooner - SIGNS-for-Kids: developing an illness recognition tool to connect home and hospital
}

Jonathan Gilleland (D , , David Bayfield, ${ }^{2}$ Ann Bayliss, ${ }^{3,4}$ Karen Dryden-Palmer, ${ }^{5}$ Joelle Fawcett-Arsenault, ${ }^{6}$ Michelle Gordon, ${ }^{7,8}$ Dawn Hartfield, ${ }^{9}$ Anthony lacolucci, ${ }^{10}$ Melissa Jones, ${ }^{11}$ Lisa Ladouceur, ${ }^{12}$ Martin McNamara, ${ }^{2}$ Kristen Middaugh, ${ }^{13}$ Gregory Moore, ${ }^{14,15}$ Sean Murray, ${ }^{16}$ Joanna Noble, ${ }^{17}$ Simran Singh, ${ }^{18}$ Jane Stuart-Minaret, ${ }^{18}$ Carla Williams, ${ }^{19}$ Christopher S Parshuram ${ }^{5,20}$

To cite: Gilleland J, Bayfield D, Bayliss A, et al. Severe illness getting noticed sooner - SIGNSfor-Kids: developing an illness recognition tool to connect home and hospital. BMJ Open Quality 2019;8:e000763. doi:10.1136/ bmjoq-2019-000763

- Additional material is published online only. To view please visit the journal online (http://dx.doi.org/10.1136/ bmjoq-2019-000763).

Received 29 July 2019 Revised 9 0ctober 2019 Accepted 1 November 2019

Check for updates

(C) Author(s) (or their employer(s)) 2019. Re-use permitted under CC BY-NC. No commercial re-use. See rights and permissions. Published by BMJ.

For numbered affiliations see end of article.

Correspondence to Dr Jonathan Gilleland; jonathan.gilleland@ahs.ca

\section{ABSTRACT}

Background Delays to definitive treatment for timesensitive acute paediatric illnesses continue to be a cause of death and disability in the Canadian healthcare system. Our aim was to develop the SIGNS-for-Kids illness recognition tool to empower parents and other community caregivers to recognise the signs and symptoms of severe illness in infants and children. The goal of the tool is improved detection and reduced time to treatment of acute conditions that require emergent medical attention. Methods A single-day consensus workshop consisting of a 17-member panel of parents and multidisciplinary healthcare experts with content expertise and/or experience managing children with severe acute illnesses was held. An a priori agreement of $\geq 85 \%$ was planned for the final iteration SIGNS-for-Kids tool elements by the end of the workshop.

Results One hundred percent consensus was achieved on a five-item tool distilled from 20 initial items at the beginning of the consensus workshop. The final items included four child-based items consisting of: (1) behaviour, (2) breathing, (3) skin, and (4) fluids, and one context-based item and (5) response to rescue treatments. Conclusions Specific cues of urgent child illness were identified as part of this initial development phase. These cues were integrated into a comprehensive tool designed for parents and other lay caregivers to recognise the signs of serious acute illness and initiate medical attention in an undifferentiated population of infants and children. Future validation and optimisation of the tool are planned.

\section{BACKGROUND}

Improving the outcomes of acute severe illness is contingent on the availability, timing and application of effective treatments. For our purposes, acute severe illness is any illness that could result in death or significant morbidity if not identified early or where treatment is significantly delayed. Fortunately, for many common acute severe illnesses (eg, sepsis), well-defined treatments are available (eg, antibiotics, source control, circulatory and respiratory support). ${ }^{1}$ Timing is a central element of acute care particularly for conditions like sepsis and trauma. Established literature and internationally accepted guidelines underscore the clinical importance of timely treatment. $^{12}$ The Society of Critical Care Medicine slogan 'Right Care, Right Now'3 further emphasises the relevance of these foundational principles of acute care.

Unfortunately, many recent studies of early protocolised goal-directed treatment for severe life-threatening illness such as septic shock have failed to demonstrate a mortality benefit in adult and paediatric populations. ${ }^{45}$ This is likely in part due to widespread improvement in system and patient-level care resulting in overall in-hospital mortality that is now much lower for adult and paediatric populations compared with historical cohorts. ${ }^{67}$ Further reductions in mortality may be achieved by understanding and shortening the duration from symptom onset to definitive treatment. In a series of infants with bacterial meningitis in the UK, $24 \%$ presented to the hospital $>24$ hours after symptom development $^{8}$; this seemingly delayed presentation was associated with both increased mortality and neurologic morbidity. ${ }^{9}$ Other severe illnesses including stroke, ${ }^{1011}$ malignancy ${ }^{12-14}$ and kernicterus ${ }^{1516}$ can result in permanent injury and are also time-sensitive in terms of their need for definitive treatment. Furthermore, multiple jurisdictions in Canada, the USA and the UK have reported that children under 1 year of age are at greatest risk of death from medical conditions related to prematurity, congenital anomalies and infections with anywhere from $8 \%$ to $26 \%$ of deaths having 
some degree of preventability. ${ }^{817-19}$ Contributory themes to these deaths are multifactorial and include: (1) delays in seeking care, (2) delays in recognition of symptoms and abnormal vital signs at various levels of the healthcare system, (3) poor team communication and (4) a lack of continuity of care particularly at transitions of care. ${ }^{8}$

The under-recognition of severe acute illness in hospital settings was the impetus for the development and implementation of medical emergency teams ${ }^{20} 21$ and early warning scores. ${ }^{22} 23$ When integrated with other system-level interventions, paediatric early warning scores reduce serious safety events ${ }^{24}$ and significant clinical deterioration events. ${ }^{23}$ Early identification of illness in a community setting prior to hospital admission is the next logical extension of this paradigm and necessarily relies on family members to recognise and act on the evolving features of severe acute illness in their child. Family triggered activation of medical emergency teams is integrated into many paediatric hospitals ${ }^{25} 26$ and family assessment is acknowledged in the safety literature as paramount in illness recognition requiring urgent medical attention. $^{13} 27$ In outpatient settings, symptom checklists, ${ }^{28}$ illness severity action plans ${ }^{29}$ and parent early warning scores ${ }^{30}$ have been described predominantly in selected populations with known disorders and more predictable symptoms. A parent early warning score for infants with complex congenital heart disease has demonstrated good acceptance and feasibility by parents but requires attention to parent preparation and confidence in the use of the instrument. ${ }^{30}$ These examples demonstrate that an understanding of the signs and symptoms of severe acute illness progression and the populations at greatest risk are important. To our knowledge, a validated and accessible early warning tool designed to help parents and other members of the lay public identify often undifferentiated severe acute illness across the spectrum of childhood age and development does not currently exist.

In 2016, the Healthcare Insurance Reciprocal of Canada (HIROC) determined that 'failure to escalate medical treatment stemming from under-recognition of severe illness in hospitalised children' in its top acute care risks leading to litigation for healthcare providers and organisations. ${ }^{31}$ In conjunction with the Canadian Patient Safety Institute (CPSI) and HIROC, this project was initiated with a focus on the developing an early recognition tool for families and other community-based caregivers to detect the signs of severe acute illness and help to translate their concerns during the initial interactions with the healthcare system. This may lead to further reductions in preventable morbidity and mortality by (1) improving transitions to and within hospital settings and (2) earlier initiation of definitive medical treatment.

\section{METHODS}

A panel of experts was selected from across Canada with a diverse spectrum of perspectives and disciplines who frequently manage children with severe acute illness and/or have in-depth knowledge of the associated signs and symptoms in either a clinical or forensic capacity. The panel was limited to a maximum of three participants from any one group or perspective to maintain a manageable panel size and limit over-representation from any one key stakeholder group. A consensus development workshop $^{32}$ incorporating at least three stages of consensusbuilding was planned using elements of nominal group technique $^{3435}$ to generate and distill signs of serious acute illness in children was planned with and an a priori consensus of $\geq 85 \%$ on the final tool elements. An illness threshold to guide the tool development was selected whereby immediate escalation of care to an emergency department would be appropriate and the tool needed to have good applicability across all paediatric age categories ranging from term newborns to adolescents. Selected pre-reading material was distributed to panel members to provide context on the topic of symptom recognition in different scenarios by parents and lay care providers. The material included several published symptom checklists of severe illness designed for lay people and articles describing important signs and symptoms of severe infection in infants and the use of parental early warning scores in infants with complex congenital heart disease. ${ }^{283036}$ Initial evaluation of the construct validity of the SIGNs-for-Kids tool planned for an informal review of 10 randomly selected paediatric case files held by HIROC of delayed recognition of severe illness causing death or disability that resulted in legal claims. Selected cases were reviewed to determine the presence of one or more of the SIGNS criteria. It was hypothesised that most cases would have documentation indicating the presence of one or more of the SIGNS-for-Kids items.

\section{Patient and public involvement}

The initial research question was identified by HIROC based on themes observed in medical-legal claims made on behalf of paediatric patients related to failure to escalate medical treatment in the Canadian healthcare setting. This finding was endorsed and championed by the CPSI, a not-for-profit organisation with a mission to advance a culture committed to sustained improvement for safer healthcare. At the inception of this project, the authors and the CPSI were committed to the inclusion of parents of paediatric patients with significant experience of the healthcare system throughout the consensus process, manuscript development and all future steps leading from this research. Various organizations including the Canadian Patient Safety Institute and Patients for Patient Safety Canada provided parent candidates from which the parent representatives were selected.

\section{RESULTS}

A 17-member expert panel was formed (online supplementary appendix 1). Its members were representative of three Canadian provinces and included experience from the coroner's office, two parents of children with 
extensive healthcare system experience and multiple paediatric healthcare provider groups and specialties. The disciplines and specialties included inpatient paediatricians, paediatric and neonatal intensive care, emergency medicine, community paediatricians, a clinical nurse specialist, a respiratory therapist, primary care nurse practitioner and healthcare providers for remote Indigenous populations. The panel subsequently met in Toronto in May 2018 over 1 day. CPSI and HIROC provided financial support for travel and lodging for panel members to attend if they lived out of town.

An initial interactive facilitated discussion began the first stage of the consensus workshop. The group discussed and developed a comprehensive list of signs and symptoms of evolving severe acute illness that should prompt childcare givers to seek out urgent medical attention. The panel determined that the severity of illness indications to trigger an escalation in care should be independent of experience with the healthcare system or relationships with healthcare providers; be observable and detectable by lay members of the community; be inappropriate or unreasonable to ignore as they could represent the presence of a life-threatening condition; and be credible with frontline healthcare professionals who would interact with children whose parents were prompted to seek urgent medical attention.

In the second stage, each participant was asked to individually rank the top three signs or symptoms according to the participant's perceptions of importance in detecting severe acute illness in infants and children. The ranked list of signs and symptoms was then re-presented to the group and were sub-categorised via group consensus into child-based cues and context-based cues. This resulted in 10 child-based cues and 2 context-based cues.

In the third stage, the panel was asked to examine the ranked items for shared themes that would allow them to be distilled into overarching individual tool components. This resulted in the identification of four stand-alone items into which other ranked items were integrated and used as descriptors. A fourth stage was added for the group to reflect on the included items and ensure that the a priori consensus threshold and reach agreement on the final product (figure 1). In this final review, $100 \%$ of the members reached agreement after the addition of a category describing lack of response to either prescribed or over-the-counter treatment that may have been initiated prior to seeking medical attention. The wording and definitions of the items were discussed, refined for lay language and accessibility to a wide range of end-users. Phrasing, presentation and design elements were discussed to facilitate the rapid interpretation and utilisation by parents or other nonhealthcare professional caregivers in both English and French. This resulted in the articulation of the five SIGNS items:

1. Behaviour: (a) reduced interaction with surroundings; (b) reduced independent actions; (c) persisting uncontrolled movements or lack of movement.
2. Breathing: (a) noticeable breathing; (b) long pauses between breaths.

3. Skin: (a) jaundice in the first month of life; (b) mottled and cold skin (with other concerns); (c) blue (ish) skin and tongue; (d) purple rash.

4. Fluids: (a) persistent vomiting; (b) colourful vomiting (red or green); (c) minimal fluid intake; (d) No urine.

5. Response to rescue treatments: (a) known health issue getting worse despite the use of usually effective treatment.

Ten randomly selected cases of delayed recognition of severe illness leading to death or disability that resulted in medical-legal claims were subsequently reviewed from the HIROC database and confirmed the presence of at least one SIGNS-for-Kids criteria in each case.

\section{DISCUSSION}

We describe the first phase of development of the SIGNSfor-Kids (SIGNES Enfant) tool-a five-item public health tool to; (1) help parents and other lay-caregivers identify acute severe illness in children, and (2) support the articulation and efficient communication of parental and lay concerns to healthcare professionals and (3) to facilitate timely escalation of care. The selected signs, criteria and cues align with other tools listing symptoms described in case series of severe infection in infants, ${ }^{96}$ the criteria of the Advanced Paediatric Life Support assessment triangle ${ }^{37}$ the lived experience of a diverse group of paediatric clinicians, the perspectives of parental representatives and selected cases of delayed recognition of severe illness resulting in medical-legal action. The panel's selection of severe acute illness as a threshold was a balancing principle to prevent adversely increasing attendance at emergency departments for children who did not require urgent medical attention as this could have counterproductive service delivery effects at the system level. Ultimately, the panel envisioned a tool to help prevent community cases of failure-to-rescue leading to death or disability that occur despite the presence of abnormal signs and symptoms warranting immediate medical attention.

This is the first tool created using an established development methodology that addresses the undifferentiated populations of children. Other tools have been created for patients with specific diseases (asthma management plan $)^{29}$ or broader populations of high-risk patients (cyanotic heart disease). ${ }^{30}$ The SIGNS-for-kids tool is intended to provide a comprehensive set of items describing severe illness in children with and without comorbidities across the spectrum of age and development anticipated in the paediatric population. Short semi-technical descriptions have been created for each element of the tool that will provide important clinical anchors to develop visual and language aids. Further development is required. 


\section{expert panel}

17 members from 3 Canadian provinces 6 perspectives: parent, physician, nurse, nurse practitioner, coroner, respiratory therapist.

7 disciplines: neonatology, transport, emergency care, intensive care, inpatient paediatrics, primary care, forensics.

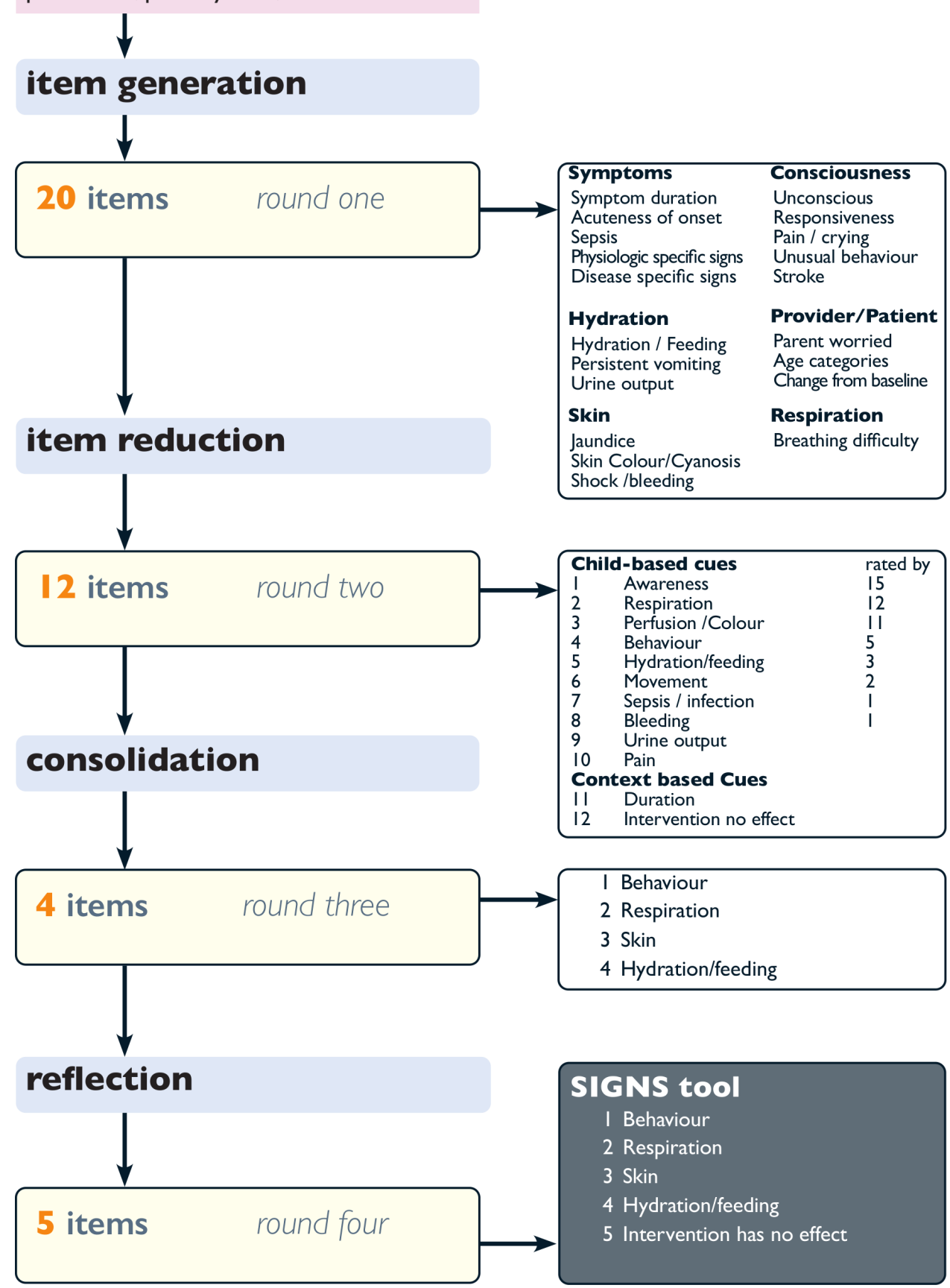

project goals

design preferences \&

ideal item properties

preparation

teleconference and pre-reading
Limitations

There are three main limitations of this work. First, tool development included a limited number of healthcare professionals. The inclusion of more representatives from each discipline may have increased the diversity of items during item generation and increased the depth of consideration during item reduction phases. Second, the development panel included two parent representatives. Biased representation linked to direct experiences of the parents is acknowledged as a possibility. For this 
reason, we chose experienced parent representatives who had been pre-screened and recommended as having both personal and broader experience as patient/parent representatives. Observations from within the panel discussion confirmed the parents were able to bracket their experiences and provide a broader perspective. Third, limited evidence of validity is provided. Overlap of the SIGNS items with tools used for triage by healthcare professionals provides face validity, however more direct measures of validity are lacking. The use of 10 cases provides evidence of initial criterion validity only as it is a small sample and does not ensure generalisability to a larger more diverse population. Further evidence is needed and is a focus of our future work.

\section{Future directions}

The development of the SIGNS-for-kids tool is the first step towards the objective of an early warning/recognition tool for use in the community by lay child caregivers. Parents and caregivers will be a key part of the future development and evaluations of the usability of the SIGN-for-Kids materials, validity of and in the evaluations of effectiveness evaluations of the SIGNS for Kids tool. Required future work will include the development and refinement of communication materials to represent the SIGNS to parents and other caregivers, demonstration of that parents and other carers can understand the items, the validation of the SIGNS items as useful markers of severe illness when applied by parents or other caregivers, and in evaluations of clinical effectiveness.

\section{CONCLUSIONS}

The SIGNS-for-kids tool addresses a previously unexplored gap in the acute severe illness recognition process for children. We think this initiative will help inform and support families and other community-based care providers to recognise the signs of severe illness, support the deployment of healthcare resources and has great potential to reduce preventable death and disability in children.

\section{Author affiliations}

${ }^{1}$ Department of Pediatrics, Section of Pediatric Intensive Care Medicine, Alberta Children's Hospital, Calgary, Alberta, Canada

${ }^{2}$ Department of Emergency Medicine, Georgian Bay General Hospital, Midland, Ontario, Canada

${ }^{3}$ Children's Health Division, Trillium Health Partners, Mississauga, Ontario, Canada

${ }^{4}$ Department of Paediatrics, University of Toronto, Mississauga, Ontario, Canada

${ }^{5}$ Department of Critical Care Medicine, Hospital for Sick Children, Toronto, Ontario,

Canada

${ }^{6}$ Patient and Family Centered Care, Stollery Children's Hospital, Edmonton, Ontario, Canada

${ }^{7}$ Department of Neonatal and Pediatric Medicine, Orillia Soldiers Memorial Hospital, Orillia, Ontario, Canada

${ }^{8}$ University of Toronto, Toronto, Ontario, Canada

${ }^{9}$ Department of Pediatrics, Division of Pediatrics, Hospital Medicine Faculty of Medicine and Dentistry, University of Alberta, Edmonton, Alberta, Canada

${ }^{10}$ Acute Care Transport Services (ACTS), Hospital for Sick Children, Toronto, Ontario, Canada

${ }^{11}$ SickKids Foundation, Hospital for Sick Children, Toronto, Ontario, Canada

${ }^{12}$ Nurse Practitioner Clinic, Georgian Bay General Hospital, Midland, Ontario, Canada
${ }^{13}$ Paediatric Critical Care Medicine, Center for Safety Research, Hospital for Sick Children, Toronto, Ontario, Canada

${ }^{14}$ Department of Obstetrics and Gynecology, Division of Newborn Care, Ottawa Hospital General Campus, Ottawa, Ontario, Canada

${ }^{15}$ Department of Pediatrics, Division of Neonatology, University of Ottawa, Ottawa, Ontario, Canada

${ }^{16} \mathrm{NEO}$ Kids and Family Program, Health Sciences North, Sudbury, Ontario, Canada ${ }^{17}$ Healthcare Insurance Reciprocal of Canada, Lead Clinical Risk, Healthcare Safety and Risk Management, Toronto, Ontario, Canada

${ }^{18}$ Department of Pediatrics, Division of Pediatric Emergency Medicine, Hospital for Sick Children, Toronto, Ontario, Canada

${ }^{19}$ Canadian Patient Safety Institute, Ottawa, Ontario, Canada

${ }^{20}$ Pediatrics, Critical Care, Health Policy, Management \& Evaluation, University of Toronto, Toronto, Ontario, Canada

Contributors JG: member of the expert panel that participated in the consensus workshop process; primary and corresponding author of the manuscript; DB, AB, KD-P, JF-A, MG, DH, Al, MJ, LL, MM, KM, GM, SM, JN, SS, JS-M, CW, CSP: members of the expert panel that participated in the consensus workshop process; contributed to and approved the final version of the manuscript.

Funding Travel and lodging compensation (if necessary) to attend the one day consensus workshop was provided by the Canadian Patient Safety Institute and the Health Insurance Reciprocal of Canada.

Competing interests None declared.

Patient consent for publication Not required.

Provenance and peer review Not commissioned; externally peer reviewed.

Data availability statement Data may be obtained from a third party and are not publicly available.

Open access This is an open access article distributed in accordance with the Creative Commons Attribution Non Commercial (CC BY-NC 4.0) license, which permits others to distribute, remix, adapt, build upon this work non-commercially, and license their derivative works on different terms, provided the original work is properly cited, appropriate credit is given, any changes made indicated, and the use is non-commercial. See: http://creativecommons.org/licenses/by-nc/4.0/.

ORCID iD

Jonathan Gilleland http://orcid.org/0000-0001-7538-2881

\section{REFERENCES}

1 Davis AL, Carcillo JA, Aneja RK, et al. American College of critical care medicine clinical practice parameters for hemodynamic support of pediatric and neonatal septic shock. Crit Care Med 2017;45:1061-93.

2 Galvagno SM, Nahmias JT, Young DA. Advanced trauma life support $^{\circledR}$ Update 2019: management and applications for adults and special populations. Anesthesiol Clin 2019;37:13-32.

3 Angood PB. Right care, right now--you can make a difference. Crit Care Med 2005;33:2729-32.

4 Rowan KM, Angus DC, Bailey M, et al. Early, goal-directed therapy for septic shock - a patient-level meta-analysis. $N$ Engl J Med 2017;376:2223-34.

5 Workman JK, Ames SG, Reeder RW, et al. Treatment of pediatric septic shock with the surviving sepsis campaign guidelines and PICU patient outcomes. Pediatr Crit Care Med 2016;17:e451-8.

6 Wolfler A, Osello R, Gualino J, et al. The importance of mortality risk assessment: validation of the pediatric index of mortality 3 score. Pediatr Crit Care Med 2016;17:251-6.

7 Nguyen HB, Jaehne AK, Jayaprakash N, et al. Early goal-directed therapy in severe sepsis and septic shock: insights and comparisons to process, promise, and arise. Crit Care 2016;20.

8 Office of the Chief Coroner PoO. Paediatric death review Committee and deaths under five Committee (annual report, 2016.

9 Okike IO, Ladhani SN, Johnson AP, et al. Clinical characteristics and risk factors for poor outcome in infants less than 90 days of age with bacterial meningitis in the United Kingdom and ireland. Pediatr Infect Dis J 2018;37:837-43.

10 Sherman V, Greco E, Moharir M, et al. Feeding and swallowing impairment in children with stroke and unilateral cerebral palsy: a systematic review. Dev Med Child Neurol 2019;61:761-9.

11 McKinney SM, Magruder JT, Abramo TJ. An update on pediatric stroke protocol. Pediatr Emerg Care 2018;34:810-5.

12 Lowe EJ, Pui C-H, Hancock ML, et al. Early complications in children with acute lymphoblastic leukemia presenting with Hyperleukocytosis. Pediatr Blood Cancer 2005;45:10-15. 
13 Handa A, Nozaki T, Makidono A, et al. Pediatric oncologic emergencies: clinical and imaging review for pediatricians. Pediatr Int 2019;61:122-39.

14 Stephanos K, Picard L. Pediatric oncologic emergencies. Emerg Med Clin North Am 2018;36:527-35.

15 Kaplan M, Bromiker R, Hammerman C. Severe neonatal hyperbilirubinemia and kernicterus: are these still problems in the third millennium? Neonatology 2011;100:354-62.

16 Johnson L, Bhutani VK, Karp K, et al. Clinical report from the pilot USA kernicterus registry (1992 to 2004). J Perinatol 2009;29 Suppl $1:$ S25-45.

17 Rimsza ME, Schackner RA, Bowen KA, et al. Can child deaths be prevented? the Arizona child fatality review program experience. Pediatrics 2002;110:e11.

18 Magnus DS, Schindler MB, Marlow RD, et al. A service evaluation of a hospital child death review process to elucidate understanding of contributory factors to child mortality and inform practice in the English National health service. BMJ Open 2018;8:e015802.

19 Pearson GA, Ward-Platt M, Harnden A, et al. Why children die: avoidable factors associated with child deaths. Arch Dis Child 2011:96:927-31.

20 Devita MA, Bellomo R, Hillman K, et al. Findings of the first consensus conference on medical emergency teams. Crit Care Med 2006;34:2463-78.

21 Kotsakis A, Lobos AT, Parshuram C, et al. Implementation of a multicenter rapid response system in pediatric academic hospitals is effective. Pediatrics 2011;128:72-8.

22 Parshuram CS, Hutchison J, Middaugh K. Development and initial validation of the bedside paediatric early warning system score. Crit Care 2009;13.

23 Parshuram CS, Dryden-Palmer K, Farrell C, et al. Effect of a pediatric early warning system on all-cause mortality in hospitalized pediatric patients: the epoch randomized clinical trial. JAMA 2018;319:1002-12.

24 Muething SE, Goudie A, Schoettker PJ, et al. Quality improvement initiative to reduce serious safety events and improve patient safety culture. Pediatrics 2012;130:e423-31.
25 Brady PW, Zix J, Brilli R, et al. Developing and evaluating the success of a family activated medical emergency team: a quality improvement report. BMJ Qual Saf 2015;24:203-11.

26 Gill FJ, Leslie GD, Marshall AP. The impact of implementation of Family-Initiated escalation of care for the deteriorating patient in hospital: a systematic review. Worldviews Evid Based Nurs 2016;13:303-13.

27 Canadian Agency for Drugs and Technologies in Health. Patient-and Family-Centered care initiatives in acute care settings: a review of the clinical evidence, safety and guidelines. Ottawa, ON: Canadian Agency for Drugs and Technologies in Health, 2015.

28 Hallisy J. Empowered patient: ten warnings of a rapidly deteriorating patient. Canadian Patient Safety Institute, 2011.

29 MacGillivray ME, Flavin MP. Canadian paediatric asthma action plans and their correlation with current consensus guidelines. Paediatr Child Health 2014;19:362-6.

30 Gaskin KL, Wray J, Barron DJ. Acceptability of a parental early warning tool for parents of infants with complex congenital heart disease: a qualitative feasibility study. Arch Dis Child 2018;103:880-6.

31 Canada HIRo. 2016 HIROC acute care top risks, 2016

32 Halcomb E, Davidson P, Hardaker L. Using the consensus development conference method in healthcare research. Nurse Res 2008;16:56-71.

33 Sabir M, Breckman R, Meador R, et al. The CITRA research-practice consensus-workshop model: exploring a new method of research translation in aging. Gerontologist 2006;46:833-9.

34 Gallagher M, Hares T, Spencer J, et al. The nominal group technique: a research tool for general practice? Fam Pract 1993;10:76-81.

35 McMillan SS, King M, Tully MP. How to use the nominal group and Delphi techniques. Int J Clin Pharm 2016;38:655-62.

36 Okike IO, Ladhani SN, Anthony M, et al. Assessment of healthcare delivery in the early management of bacterial meningitis in UK young infants: an observational study. BMJ Open 2017;7:e015700.

37 Pediatrics ACoEPaAAo. The pediatric emergency medicine course. 3rd edn. Dallas, TX: American College of Emergency Physicians and American Academy of Pediatrics, 1998 